\title{
Classification of Aggression and Social Withdrawal in Early Childhood and Its Associations with Peer Competence: Using Latent Profile Analysis
}

\author{
Yie Lae Kim¹, Sunhee Kim² \\ M. A., Department of Child Development and Family Studies, Pusan National University, Busan, Korea ${ }^{1}$ \\ Professor, Department of Child Development and Family Studies, Pusan National University, Busan, Korea ${ }^{2}$ \\ 유아의 공격성과 사회적 위축 잠재집단유형에 따른 또래유능성: 잠재프로파 \\ 일 분석을 중심으로 \\ 김이래 ${ }^{1}$, 김선희 ${ }^{2}$ \\ 부산대학교 아동가족학과 석사 ${ }^{1}$ 부산대학교 아동가족학과 교수 ${ }^{2}$
}

Objectives: The purpose of this study is to investigate profiles of aggression and social withdrawal in early childhood, using the latent profile analysis to identify differences in peer competence among profiles groups.

Methods: The participants were 376 children, ages 3 through 5, in four kindergarten classes and five daycare centers in Busan, and their teachers. For data analysis, this study applied a latent profile analysis, to derive latent profile groups, and a three-step approach, to determine whether there was a significant difference in peer competence among profile groups.

Results: Aggression and social withdrawal in early childhood were found in five profile groups; Middle aggression/Low social withdrawal (25.1\%), Low aggression/Unsociability dominated (5.7\%), Middle aggression/Middle social withdrawal (44.7\%), Low aggression/High shyness and unsociability (11.4\%), and High aggression/High social withdrawal (13.1\%). There were differences in the level of peer competence (sociality, prosocial behavior, and leadership) in five profile groups of aggression and social withdrawal.

Conclusion: The results provide basic data for the program to help those children who show maladaptive behaviors in early childhood educational institutions.

Keywords: aggression, social withdrawal, peer competence, latent profile analysis

\section{Introduction}

유아들은 유아교육기관에서 많은 시간을 보내기 때문에 또 래 및 교사와의 원만한 관계 형성은 유아교육기관 적응에 중 요한 요인이다. 하지만 문제행동을 보이는 유아는 이러한 관 계 형성과 적응에 어려움을 겪는다(Coplan, Ooi, Rose-Krasnor, \& Nocita, 2014; J. H. Kim, 2010; Ladd \& Burgess, 1999; Yoon \&

Corresponding Author: Sunhee Kim, Professor, Department of Child Development and Family Studies, Pusan National University, 2, Busandaehak-ro 63beon-gil, Geumjeong-gu, Busan, Korea

E-mail: kremedy@pusan.ac.kr
Kim, 2011). 유아기 문제행동은 크게 외현화 문제행동과 내재 화 문제행동으로 구분된다(Achenbach \& Edelbrock, 1983). 유 아기 외현화 문제행동은 자신의 정서와 행동을 통제하는 데 있어 어려움이 외부로 표출되어 공격성, 주의집중문제와 같은 행동화로 나타나며, 유아기 내재화 문제행동은 자신의 정서와 행동을 지나치게 억제하거나 표현하지 못하여 불안과 우울과 같은 정서적 문제를 야기하고 이는 위축된 행동으로 나타난

(C)The Korean Association of Child Studies

This is an Open Access article distributed under the terms of the Creative Commons Attribution Non-Commercial License (http:// creativecommons.org/licenses/by-nc/4.0) which permits unrestricted noncommercial use, distribution, and reproduction in any medium, provided the original work is properly cited. 
다. 유아기의 대표적인 문제행동인 공격성과 사회적 위축(K. S. Lee, Shin, Chun, \& Park, 2004)의 발달과정에 관한 다수의 연구들(Coplan, Ooi, Xiao, \& Rose-Krasnor, 2018; Crick, 1997; Crick \& Grotpeter, 1995; Ko \& Sung, 2019)은 그 원인을 규명하 고 중재 방안을 모색하기 위해 각 문제행동의 하위유형에 관 심을 가져왔다.

공격성은 넓은 범주에서 외현화 문제행동으로 분류되며, 일 반적으로 신체적 공격성과 관계적 공격성으로 구분된다(Crick $\&$ Grotpeter, 1995). 신체적 공격성은 밀기, 때리기, 발로 차기와 같이 타인에게 신체적 해를 입히거나 위협을 가하는 행동이며, 관계적 공격성은 특정 유아에 대한 나쁜 소문내기와 같은 행동 으로 또래들 사이의 관계를 조절하고 방해하여 집단에서 배척 또는 소외시키는 행위로 정의된다(Crick, 1997).

공격성과 대조적으로 사회적 위축은 넓은 범주에서 내재 화 문제행동으로 분류되며, 사회적 상호작용에 개입하지 않거 나 다른 아이들과 놀지 못하는 것을 의미한다(Coplan, Prakash, O’Neil, \& Armer, 2004). 유아의 사회적 위축은 표면적으로 볼 때 단순히 또래와의 상호작용이 적은 것으로 보이지만, 사회 적 참여에 대한 내면적 동기인 접근 및 회피 동기에 따라 갈등 적 수줍음, 사회적 무관심, 사회적 회피로 구분된다(Coplan et al., 2018). 갈등적 수줍음은 또래에게 접근하고자 하는 접근 동기와 또래를 회피하고자 하는 회피 동기가 모두 높아 내적 인 갈등이 일어나는 것으로 이 유형의 유아는 또래 주변을 맴 돌거나 놀이를 구경하는 등 억제된 행동과 낮은 사회적 상호 작용 행동을 보인다. 사회적 무관심은 접근 동기가 낮아 또래 와 상호작용에 덜 참여하는 것으로 평가되며, 또래와 상호작 용하는 것보다 장난감과 같은 사물에 더 흥미를 보인다. 마지 막으로, 사회적 회피는 접근 동기가 낮은 반면 회피 동기가 높 아 사회적 상호작용을 적극적으로 회피하는 모습이 특징이다.

한편, 공격성과 사회적 위축은 분명 다른 문제행동 범주 안에 있지만, 유아가 나타내는 문제행동들이 정확하게 하나 의 문제행동 범주로 분류되지 않는다(Keiley, Lofthouse, Bates, Dodge, \& Pettit, 2003; J. R. Lee, Kim, Yi, Song, \& Kim, 2017; Lilienfeld, 2003). 유아의 공격성과 같은 외현화 문제행동과 사 회적 위축과 같은 내재화 문제행동은 높은 관련성이 있어 함 께 나타나기도 한다(M. S. Kim, Ha, \& Oh, 2014). 4, 5, 6세 유 아의 문제행동 프로파일을 분석한 연구에서 외현화와 내재 화 문제행동이 낮은 '문제없는'집단, 외현화와 내재화 문제행 동이 평균보다 약간 높은 '일반'집단, 외현화 문제행동이 연령 에 따라 점차 증가하고 내재화 문제행동이 임상수준을 넘어선 ‘위험'집단을 확인하였다(J. R. Lee et al., 2017). 이는 유아의 문
제행동 양상이 다양하게 나타나며, 이에 따라 문제행동을 줄 이기 위한 개입과 방안이 달라져야 함을 시사한다. 따라서 본 연구는 유아기 대표적인 문제행동인 공격성과 사회적 위축을 동시에 고려하여, 유아 개인마다 어떠한 양상으로 나타나는지 탐색하고자 한다.

유아의 공격성과 사회적 위축을 함께 고려한 연구들에서 유아의 공격성과 사회적 위축 수준에 따라 잠재집단을 구분한 결과, 공격성 수준이 높고 사회적 위축 수준이 낮은 집단, 사회 적 위축 수준이 높고 공격성 수준이 낮은 집단, 공격성과 사회 적 위축 수준이 둘 다 높은 집단, 공격성과 사회적 위축 수준이 둘 다 낮은 집단이 확인되었다(Farmer, 2000; Ladd \& Burgess, 1999; Ledingham \& Schwartzman, 1984). 즉, 유아의 공격성과 사회적 위축이 함께 나타날 수 있으며, 그 수준에 따라 여러 집 단으로 구분됨을 확인하였다. 하지만 위의 선행연구들은 공격 성과 사회적 위축의 하위 유형을 함께 고려하지 못했다는 한 계점이 있다. 다양한 유형으로 구분되는 공격성과 사회적 위 축은 유아 개인에 따라 다양한 양상으로 드러난다. 기존 연구 에서 유아 개개인은 신체적 - 관계적 공격성 수준에 따라 네 가 지 잠재집단 즉, 신체적 공격성이 높은 집단, 관계적 공격성이 높은 집단, 신체적 공격성과 관계적 공격성 둘 다 높은 집단, 신체적 공격성과 관계적 공격성 둘 다 낮은 일반 집단 중 한 집 단에 분류되었다(Crick, 1997; Shin, 2008). 또한, 개별 유아는 사회적 위축의 각 하위 유형인 갈등적 수줍음, 사회적 무관심, 사회적 회피 수준에 따라 다양한 잠재집단으로 구분될 수 있 다. 이를 통해, 유아의 공격성과 사회적 위축의 하위유형에 따 라 다양한 잠재집단이 나타날 수 있음을 예측할 수 있다.

이에 본 연구는 사람 중심적(person-oriented) 접근 방법 인 잠재프로파일 분석(latent profile analysis)을 적용하여 유아 의 공격성과 사회적 위축 잠재집단유형을 파악하고 각 잠재 집단별 특성을 살펴보고자 한다. 기존 연구들은 변수 중심적 (variable-oriented) 접근 방법으로 임의의 점수를 기준으로 특 정 집단에 속하는 유아의 특성을 비교하고 차이를 검증하는 결정론적 관점으로 개별 유아가 보이는 다양한 문제행동 특성 을 고려할 수 없다는 제한점이 있다. 즉, 기준 점수를 통해 분 류된 집단에 속한 유아들은 모두 동일한 특성을 가진 것으로 간주한다. 여기서 임의의 기준 점수로 분류되어 한 집단에 속 한 모든 유아들의 특성은 과연 동일한가에 대한 의문을 제기 할 수 있다. 잠재프로파일 분석은 변수 중심적 접근 방법과 달 리 모집단 내 이질성을 허용하여 개인의 특성에 관심 기울이 는 사람 중심적(person-oriented) 접근 방법으로 모집단 내 하 위집단의 특성을 파악하기 유용하다(Bergman \& Magnusson, 
1997). 따라서 본 연구는 잠재프로파일 분석을 통해 유아기에 나타나는 공격성과 사회적 위축의 다양한 유형을 추정함으로 써 각 유형 간의 이질적 특성을 규명하고자 한다.

더불어 유아의 공격성과 사회적 위축 잠재집단유형이 또래 유능성에서 어떤 차별적 특성을 보이는지 파악하고자 한다. 또래와 긍정적인 관계를 형성하고 이를 효과적으로 유지함과 동시에 또래관계 내에서 적합한 방법으로 자신의 목표를 달성 하는 능력을 또래유능성이라 한다(J. Park \& Rhee, 2001). 또래 유능성이 높은 유아는 또래에게 잘 수용되며 심리적으로 건강 하고 적응을 잘하는 반면(Johnson, Ironsmith, Snow, \& Poteat, 2000), 또래유능성이 낮은 유아는 또래에게 거부되거나 고립 되기 쉬우며(S. Y. Kim \& Jung, 2001), 사회적 적응에 어려움이 있으므로 유아교육기관 적응에 있어 유아의 또래유능성은 필 요한 능력이다.

성공적인 또래관계를 맺는데 중요한 능력인 또래유능성 은 공격성 및 사회적 위축과 관련성이 있는 것으로 보고되고 있다(J. Y. Park, Kang, \& Kwon, 2010; Shin, 2009; Yoon \& Kim, 2011). 관계 맺기에 있어 부적절한 행동양식을 보이는 공격성 행동은 또래거부와 낮은 또래유능성과 관련이 있다(J. Y. Park et al., 2010). 구체적으로 공격성의 하위유형과 또래유능성과 의 관계를 살펴보면 신체적 공격성을 보이는 유아는 또래에게 수용되지 못하고 이로 인해 심리사회적 부적응을 경험하며, 낮은 친사회성과 낮은 사회적 유능감을 보였다(Ladd, Price, \& Hart, 1990). 관계적 공격성을 보이는 유아는 신체적 공격성 유아들처럼 사회적 부적응을 경험하지만(Crick \& Grotpeter, $1995)$ 친사회성 및 사회적 유능감과는 정적인 상관을 보였다 (Shin, 2008; Yoon \& Kim, 2011). 이는 관계적 공격 성향을 보 이는 유아들이 또래에 비해 성숙하고 사회적 지능 수준이 높 다는 것과(Björkqvist, Österman, \& Kaukianen, 1992), 언어적 기 술뿐만 아니라 사회인지적 기술이 관계적 공격성 전략의 발달 에 중요한 역할을 하기 때문으로 보인다(Crick, 1997). 이처럼 유아의 공격성 하위유형에 따라 나타나는 또래유능성의 차이 를 통해 문제행동 잠재집단유형에 따라서 또래유능성에 차이 가 나타날 수 있음을 예측할 수 있다.

사회적 위축 유아는 사회적 불안과 함께 자신의 사회적 기 술이 부족하다는 믿음을 가지고 있으며(Younger \& Daniels, 1992), 실제로도 사회적 기술이 결핍되어 사회적 문제 해결 에 있어 부적응적인 정보처리 양식을 보인다(Rubin, DanielBeirness, \& Bream, 1984). 때문에 사회적으로 위축된 유아는 교 육기관에서 또래관계의 어려움으로 부적응을 경험할 수 있으 며(Rubin, Coplan, \& Bowker, 2009), 낮은 친사회성과도 관련
됨이 보고되고 있다(Shin, 2009). 반면에 일부 연구에서 사회적 위축이 교육기관의 부적응과 관련이 없음을 보고하고 있으며 (Coplan et al., 2018; Coplan \& Weeks, 2009), 친사회성과 정적인 상관을, 또래거절 및 또래관계의 어려움과 유의한 상관을 보 이지 않는다는 선행연구 결과도 있다(Farmer, 2000; J. H. Kim, 2010; Ladd \& Burgess, 1999). 이처럼 상반된 연구결과의 이유 는 사회적 위축의 하위유형에 따라 또래유능성에서 차이가 나 타나기 때문으로 추측해 볼 수 있다. 사회적 위축의 하위유형 별 또래관계와 적응과의 관계를 비교한 연구를 살펴보면 높은 접근 동기와 높은 회피 동기로 내적인 갈등을 경험하는 갈등적 수줍음을 보이는 유아와 낮은 접근 동기와 높은 회피 동기를 가진 사회적 회피 유아는 또래문제와 불안 우울과 같은 내재화 문제를 보였지만, 낮은 접근 동기를 가진 사회적 무관심 유아 는 또래문제 및 내재화 문제와 관련이 나타나지 않았다(Coplan et al., 2018). 또한 사회적 무관심 유아는 또래거절을 경험하지 않았고 사회적으로 유능하다는 연구결과가 있다(Harrist, Zaia, Bates, Dodge, \& Pettit, 1997). 이를 통해 유아의 사회적 위축의 유형별 접근이 중요함을 다시 한 번 확인할 수 있다.

한편, 공격성과 사회적 위축 수준이 모두 높은 유아가 또래 관계에서 가장 어려움을 겪는 것으로 보고된다. 공격성 수준 이 높은 집단, 사회적 위축 수준이 높은 집단과 비교하여 공격 성과 사회적 위축 수준 모두 높은 집단은 또래수용이 낮고 상 호작용하는 친구의 수가 적었으며, 높은 외로움과 낮은 사회 적 만족감을 나타냈다(Ladd \& Burgess, 1999). 즉, 유아의 공격 성과 사회적 위축의 잠재집단에 따라 또래관계 양상이 다르게 나타나며 이는 교육기관 적응과 관련된 또래유능성이 다르게 나타남을 예상할 수 있다. 따라서 유아의 공격성과 사회적 위 축의 잠재집단유형에 따른 또래유능성 차이를 규명하여 각 잠 재집단이 가지는 특징을 파악하고자 한다.

본 연구 목적은 첫째, 유아기에 나타나는 공격성과 사회적 위축의 잠재집단 확인 및 각 잠재집단별 특성을 살펴보고, 둘 째, 잠재집단에 따라 유아의 또래유능성이 어떠한 차이를 보 이는지 파악하는 것이다. 이를 통해 유아기 공격성과 사회적 위축에 대한 이해 및 이들 유형과 또래유능성에 대한 이해를 확장함으로써 공격성과 사회적 위축을 보이는 유아를 도울 수 있는 기초자료를 제공할 수 있을 것으로 기대한다. 이에 따른 연구문제는 다음과 같다.

\section{연구문제 1}

유아의 공격성과 사회적 위축의 잠재집단유형은 어떻게 분류 되는가? 


\section{연구문제 2}

유아의 공격성과 사회적 위축의 잠재집단유형에 따라 또래유 능성은 차이가 있는가?

\section{Methods}

\section{연구대상}

본 연구의 대상은 $\mathrm{B}$ 시 4 개 구에 소재한 5 개 어린이집과 4 개 유치원에 재원하고 있는 만 $3,4,5$ 세 유아 376 명과 그들의 담 임교사 26명이다. 본 연구 대상의 일반적 특성은 남아 190 명 (50.5\%), 여아 186명(49.5\%)이며, 3세 172명(45.7\%), 4세 113 명(30.1\%), 5세 91명(24.2\%)으로 다음의 Table 1과 같다.

Table 1

General Characteristics of Participants

\begin{tabular}{llc}
\hline \multicolumn{1}{c}{ Characteristics } & Categories & Frequency $(\%)$ \\
\hline Gender & Boy & $190(50.5)$ \\
& Girl & $186(49.5)$ \\
Age & 3 & $172(45.7)$ \\
& 4 & $113(30.1)$ \\
& 5 & $91(24.2)$ \\
\hline
\end{tabular}

Note. $N=376$.

\section{연구도구}

$$
\text { 공격성 }
$$

유아의 공격성을 측정하기 위해서 Crick (1997) 및 Crick과 Grotpeter (1995)의 연구에서 사용한 교사 보고용 척도를 사용 하였다. 이 척도는 신체적 공격성을 측정하는 5 개 문항(예: "다 른 유아로부터 놀이감을 빼앗는다.”)과 관계적 공격성을 측 정하는 6문항(예: "자신의 요구를 들어주지 않으면 놀이집단 에 참여하지 못한다고 말로 협박한다.”)으로 총 11 개의 문항 으로 구성되었다. 이 척도는 5점 Likert 식 척도(전혀 그렇지 않 다[1점] 매우 그렇다[5점])이며 유아의 담임교사가 평소 유아 의 행동을 관찰하는 것을 기초하여 공격성 정도를 평가한다. 본 연구에서 사용된 척도 문항 구성과 하위요인별 신뢰계수 (Cronbach's $\alpha$ )는 신체적 공격성이 .81, 관계적 공격성이 92로 나타났다.

\section{사회적 위축}

사회적 위축을 측정하기 위해 Coplan 등(2018)이 개발한 Child Social Preference Scale-3 (CSPS-3)를 Ko와 Sung (2019)이 유아교 육기관에서의 사회적 위축을 교사가 평정하도록 하기 위해 수 정, 번안한 척도를 사용하였다. CSPS-3는 갈등적 수줍음 요인 7문항(예: "아이는 다른 친구가 먼저 놀이를 제안하더라도 수 줍음 때문에 함께 놀기 어려워할 것이다.”), 사회적 무관심 요 인 4문항(예: "아이는 여러 친구들과 노는 것보다 혼자서 조용 히 노는 것을 좋아한다.”), 사회적 회피 4문항(예: “아이는 다른 친구들과 놀이하는 것을 적극적으로 피한다.”)으로 총 15 문항 으로 구성되어 있으며, $8,5,12$ 번 문항은 역채점하여 사용하 도록 되어있다. 이 척도는 5점 Likert 식 척도(전혀 그렇지 않다 [1점] 매우 그렇다[5점])이며, 점수가 높을수록 사회적 위축 행동이 높음을 의미한다. 본 연구에서 사용된 척도 문항 구성 과 하위요인별 신뢰도계수(Cronbach's $\alpha$ )는 갈등적 수줍음이 .89 , 사회적 무관심이 .72 , 사회적 회피는 .87 로 나타났다.

\section{또래유능성}

또래유능성을 측정하기 위하여 J. Park과 Rhee (2001)가 개발 한 교사 보고용 척도를 사용하였다. 이 척도는 사교성 5 문항 (예: “다른 아이들에게 인기가 많다.”), 친사회성 5문항(예: “어 려움에 처한 아이를 잘 도와준다.”), 주도성 5 문항(예: “다른 아 이들이 따라 할 만한 놀이나 활동을 제안한다.”)으로 구성되었 다. 이 척도는 5점 Likert 식 척도(전혀 그렇지 않다[1점] 매우 그렇다[5점])이며 점수가 높을수록 유아가 또래관계에서 유능 하다는 것을 의미한다. 본 연구에서 사용된 척도 문항 구성과 하위요인별 신뢰도계수(Cronbach's $\alpha$ )는 사교성이 .93, 친사회 성 이 .89 , 주도성이 .90 으로 나타났다.

\section{연구절차}

본 조사는 부산시 4 개 구에 소재한 5 개 어린이집과 4 개 유치 원에 재원 중인 만 $3,4,5$ 세 유아의 담임교사를 대상으로 이루 어졌다. 유아의 공격성, 사회적 위축, 또래유능성 및 조사대상 자의 일반적 특성에 관한 내용으로 질문지를 구성하여 2018 년 12월 20일부터 2019년 2월 18일 까지 설문조사를 통해 자 료를 수집하였다. 설문 조사를 통해 회수된 설문지는 388 부 였으며, 이 중 누락되거나 불성실한 응답 자료 12 부를 제외한 376 부가 최종 분석 자료로 사용되었다. 


\section{자료분석}

본 연구의 자료분석은 SPSS 20.0 (IBM Co., Armonk, NY)과 Mplus 8 (Muthén \& Muthén, 2018)을 사용하여 다음과 같은 방 법으로 분석하였다. 첫째, 연구 대상인 만 3-5세 유아의 인구학 적 배경 특성을 알아보기 위해 빈도와 백분율을 산출하고, 각 측정도구의 신뢰도 검증을 위해 Cronbach's $\alpha$ 계수를 산출하였 다. 둘째, 유아의 공격성, 사회적 위축, 또래유능성 간의 관계를 알아보기 위해 Pearson 적률상관분석을 실시하였다. 셋째, 유아 의 공격성과 사회적 위축 잠재집단유형을 확인하기 위하여 잠 재프로파일 분석을 실시하였다. 넷째, 유아의 공격성과 사회적 위축 잠재집단유형에 따라 또래유능성의 차이를 확인하기 위 해 3단계 접근방법(three-step approach)을 실시하였다.

\section{Results}

\section{주요 변인들 간의 관계}

유아의 공격성, 사회적 위축, 또래유능성의 관련성을 알아보 기 위해 각 변인들의 기술통계치와 Pearson 적률상관계수를 산 출하여 Table 2에 제시하였다.

유아의 신체적 공격성, 관계적 공격성, 갈등적 수줍음, 사회 적 무관심, 사회적 회피와 사교성, 친사회성, 주도성의 평균을 살펴보면, 유아의 공격성의 하위유형별 평균은 신체적 공격성 2.36점, 관계적 공격성 2.40점으로 나타났다. 공격성 척도는 5
점 척도로 유아들의 신체적 공격성과 관계적 공격성은 중간 정도 수준을 보이고 있음을 의미한다. 유아의 사회적 위축의 하위유형별 평균은 사회적 무관심 2.35점, 갈등적 수줍음 2.12 점, 사회적 회피 1.91점 순으로 높게 나타났다. 사회적 위축 척 도는 5점 척도로 유아들이 사회적 무관심과 갈등적 수줍음은 중간 정도의 수준을, 사회적 회피는 중간보다 낮은 정도의 수 준을 보이고 있음을 의미한다. 유아의 또래유능성의 하위유형 별 평균은 사교성 3.33점, 주도성 3.33점, 친사회성 3.25점 순 으로 나타났다. 또래유능성 척도는 5점 척도로 유아들의 사교 성, 친사회성, 주도성은 중간보다 높은 정도의 수준을 보이고 있음을 의미한다.

상관분석 결과, 신체적 공격성은 갈등적 수줍음 $(r=.12, p<$ $.05)$ 과 사회적 회피 $(r=.29, p<.01)$ 와 유의미한 정적 상관을 보 였지만 사회적 무관심과는 상관이 없는 것으로 나타났다. 또 한 관계적 공격성은 사회적 회피 $(r=.28, p<.01)$ 와 유의미한 정적 상관을 보였지만 갈등적 수줍음과 사회적 무관심과는 상 관이 없는 것으로 나타났다.

신체적 공격성은 또래유능성의 모든 하위유형과 유의미한 부적 상관이 나타났다. 구체적으로, 사교성 $(r=-.38, p<.01)$, 친사회성 $(r=-.52, p<.01)$, 주도성 $(r=-.11, p<.05)$ 에서 유의 미한 부적 상관이 있었다. 관계적 공격성은 사교성 $(r=-17, p<$ $.01)$ 과 친사회성 $(r=-.32, p<.01)$ 과 유의미한 부적 상관을 보 였지만 주도성 $(r=.10, p<.05)$ 과는 유의미한 정적 상관이 나 타냈다.

사회적 위축의 모든 하위유형은 또래유능성과 유의미한 부 적 상관이 있는 것으로 나타났다( $r s=-.58 \sim-.15$, all $p s<.05)$.

Table 2

Means, Standard Deviations, and Correlations Among Variables

\begin{tabular}{|c|c|c|c|c|c|c|c|c|}
\hline Variables & 1 & 2 & 3 & 4 & 5 & 6 & 7 & 8 \\
\hline Physical aggression & - & & & & & & & \\
\hline 2. Relational aggression & $.67^{* *}$ & - & & & & & & \\
\hline 3. Conflicted shyness & $.12^{*}$ & .06 & - & & & & & \\
\hline 4. Social disinterest & .02 & -.04 & $.70^{* *}$ & - & & & & \\
\hline 5. Social avoidance & $.29^{* *}$ & $.28^{* *}$ & $.80^{* *}$ & $.63^{* *}$ & - & & & \\
\hline 6. Sociability & $-.38^{* *}$ & $-.17^{* *}$ & $-.45^{* *}$ & $-.39^{* *}$ & $-.35^{* *}$ & - & & \\
\hline 7. Prosocial behavior & $-.52^{* *}$ & $-.32^{* *}$ & $-.22^{* *}$ & $-.15^{* *}$ & $-.22^{* *}$ & $.78^{* *}$ & - & \\
\hline 8. Leadership & $-.11^{*}$ & $.10^{*}$ & $-.58^{* *}$ & $-.48^{* *}$ & $-.37^{* *}$ & $.77^{* *}$ & $.63^{* *}$ & - \\
\hline$M$ & 2.36 & 2.40 & 2.12 & 2.35 & 1.91 & 3.33 & 3.25 & 3.33 \\
\hline$S D$ & .79 & .88 & .68 & .66 & .65 & .73 & .70 & .74 \\
\hline
\end{tabular}

Note. $N=376$.

${ }^{*} p<.05 .{ }^{* *} p<.01$. 


\section{유아의 공격성과 사회적 위축의 잠재집단유형}

\author{
잠재프로파일 수 결정
}

잠재프로파일 수를 분류하기 위해 모형비교 검증을 실시한 결 과는 Table 3과 같다.

잠재프로파일 수가 증가할수록 $\mathrm{AIC}$ 와 $\mathrm{BIC}$ 값이 작아지므 로 6 개 모두 좋은 모형으로 볼 수 있다. Entropy는 0.8 이상이 고 1 과 가까울 때 적절한 모형이므로 6 개 모두 적절한 모형이 지만, 잠재프로파일 수가 5 개일 때 Entropy가 가장 1 에 가깝고 LMRLRTT $p$ 값은 .055, BLMR $p$ 값은 .000이므로 5개일 때 좋 은 모형이라 볼 수 있다. 더불어 이론적 해석 가능성과 간명성 을 함께 고려하여 잠재프로파일 수가 5개인 모형을 최종 모형 으로 결정하였다.
유아의 공격성과 사회적 위축 잠재프로파일의 특징

5 개 집단 프로파일은 Figure 1과 같다.

각 잠재집단의 특징을 살펴보면, 첫 번째 잠재프로파일은 평균 수준 공격성과 낮은 수준의 사회적 위축으로 '중간 공격 성/낮은 사회적 위축'으로 명명하였다. 두 번째 잠재프로파일 은 공격성과 사회적 위축이 평균보다 낮거나 평균과 비슷한 수준이지만 그 중 사회적 무관심이 가장 높게 나타나 '낮은 공 격성/사회적 무관심 우세형’으로 명명하였다. 세 번째 잠재프 로파일은 공격성과 사회적 위축 모두 평균 수준이므로 '중간 공격성/중간 사회적 위축'으로 명명하였다. 네 번째 잠재프로 파일은 공격성 수준이 낮고 갈등적 수줍음과 사회적 무관심이 높게 나타나 '낮은 공격성/높은 갈등적 수줍음 - 사회적 무관 심'으로 명명하였다. 다섯 번째 잠재프로파일은 공격성과 사

Table 3

Information Criteria and Model Fit Indices for 2 to 6 Latent Profiles

\begin{tabular}{|c|c|c|c|c|c|}
\hline No. of profiles & AIC & $\mathrm{BIC}$ & Entropy & $\begin{array}{c}\text { LMRRLRTT } \\
(p \text {-value })\end{array}$ & $\begin{array}{c}\text { BLMR } \\
(p \text {-value })\end{array}$ \\
\hline 2 & 3778.88 & 3841.75 & 0.81 & 0.00 & 0.00 \\
\hline 4 & 3367.00 & 3477.03 & 0.91 & 0.03 & 0.00 \\
\hline 5 & 3297.17 & 3430.77 & 0.92 & 0.06 & 0.00 \\
\hline
\end{tabular}

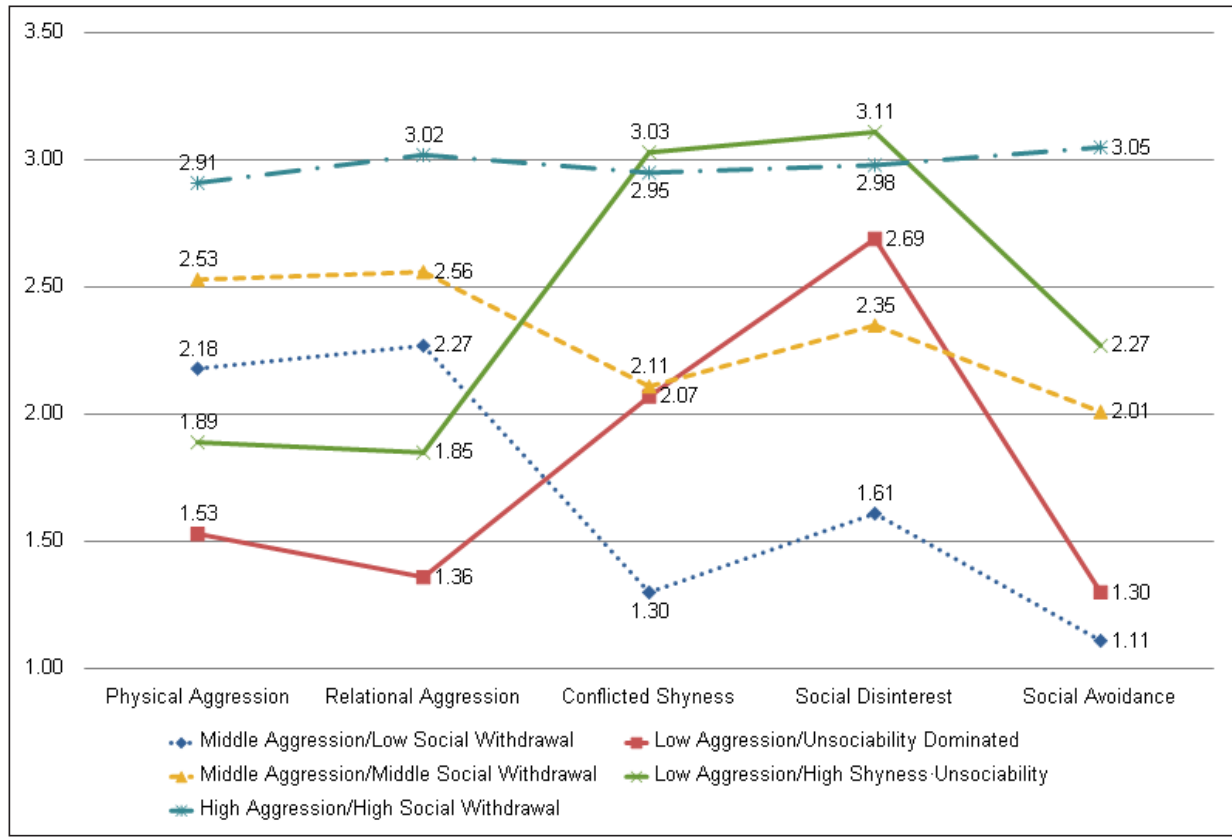

Figure 1. Characteristics of latent profiles on the indicators of aggression and social withdrawal. 
Table 4

Peer Competence by Latent Profiles of Aggression and Social Withdrawal

\begin{tabular}{|c|c|c|c|c|c|c|c|}
\hline & $\begin{array}{l}\text { Class 1. } \\
\text { Middle } \\
\text { aggression } \\
\text { /low social } \\
\text { withdrawal } \\
\quad(n=94)\end{array}$ & $\begin{array}{l}\text { Class } 2 . \\
\text { Low aggression } \\
\text { /unsociability } \\
\text { dominated } \\
\quad(n=22)\end{array}$ & $\begin{array}{l}\text { Class } 3 . \\
\text { Middle } \\
\text { aggression } \\
\text { /middle social } \\
\text { withdrawal } \\
(n=168)\end{array}$ & $\begin{array}{c}\text { Class } 4 . \\
\text { Low aggression } \\
\text { /high shyness } \\
\text { unsociability } \\
\quad(n=43)\end{array}$ & $\begin{array}{l}\text { Class } 5 . \\
\text { High aggression } \\
\text { /high social } \\
\text { withdrawal } \\
\quad(n=49)\end{array}$ & & \\
\hline & $M(S D)$ & $M(S D)$ & $M(S D)$ & $M(S D)$ & $M(S D)$ & $\chi^{2}$ & Scheffé \\
\hline Sociality & $3.80(.08)$ & $3.43(.16)$ & $3.26(.05)$ & $2.93(.10)$ & $2.99(.08)$ & $72.63^{* * *}$ & $1>2,3>5,4$ \\
\hline Prosocial behavior & $3.44(.09)$ & $3.81(.13)$ & $3.15(.53)$ & $3.20(.14)$ & $3.04(.06)$ & $36.27^{* * *}$ & $\begin{aligned} 2 & >1,4,3,5 \\
1 & >3,5\end{aligned}$ \\
\hline Leadership & $3.89(.08)$ & $3.04(.19)$ & $3.34(.05)$ & $2.51(.11)$ & $3.01(.12)$ & $120.13^{* * *}$ & $\begin{array}{c}1>3>5>4 \\
3=2,5=2\end{array}$ \\
\hline
\end{tabular}

Note. $N=376.1=$ class $1 ; 2=$ class $2 ; 3=$ class $3 ; 4=$ class $4 ; 5=$ class 5 .

${ }^{* * *} p<.001$.

회적 위축 모두 평균 이상 수준이므로 '높은 공격성/높은 사회

적 위축'으로 명명하였다.

\section{유아의 공격성과 사회적 위축 잠재집단유형에 따른 또래유능성 차이}

잠재프로파일 분석을 통해 나누어진 집단들이 또래유능성에 서 어떠한 차이를 보이는지 알아보기 위해 3 단계 접근방법 (three-step approach)을 실시한 결과는 Table 4와 같다.

3 단계 접근 결과, 모든 잠재집단은 또래유능성의 사교성 $\left(\chi^{2}\right.$ $=72.628, p<.001)$, 친사회성 $\left(\chi^{2}=36.265, p<.001\right)$ 과 주도성 $\left(\chi^{2}\right.$ $=120.126, p<.001)$ 에서 집단 간 차이가 유의하였다. 구체적 으로, 사교성은 중간 공격성/낮은 사회적 위축 집단이 가장 높 고 그 다음으로 낮은 공격성/사회적 무관심 우세형 집단과 중 간 공격성/중간 사회적 위축 집단이 그 다음으로 낮은 공격성/ 높은 갈등적 수줍음 - 사회적 무관심 집단과 높은 공격성/높 은 사회적 위축 집단 순으로 나타났다. 친사회성은 낮은 공격 성/사회적 무관심 우세형 집단이 가장 높고, 그 다음으로 중간 공격성/낮은 사회적 위축 집단이 중간 공격성/중간 사회적 위 축 집단과 높은 공격성/높은 사회적 위축 집단보다 높은 것으 로 나타났다. 주도성은 중간 공격성/낮은 사회적 위축 집단이 가장 높고, 그 다음으로 중간 공격성/중간 사회적 위축 집단이 높은 공격성/높은 사회적 위축 집단과 낮은 공격성/높은 수줍 음.무관심 집단보다 높았으며, 낮은 공격성/높은 갈등적 수줍 음.사회적 무관심 집단이 가장 낮은 것으로 나타났다.

\section{Discussion}

본 연구는 만 3-5세 유아와 교사를 대상으로 유아기 문제행동 에 있어 유아 개인 간의 이질적인 특성을 확인하기 위해 공격 성과 사회적 위축의 잠재집단유형 확인 및 잠재집단별 특성을 살펴보고, 각 잠재집단이 유아의 또래유능성에서 어떤 차별적 인 특성을 보이는지에 대해 알아보았다. 이를 통해 유아기 공 격성과 사회적 위축에 대한 이해를 넓히고 효과적인 개입을 위한 기초자료를 제공하고자 하였다. 주요 연구결과를 제시하 고 이에 대해 논의하면 다음과 같다.

첫째, 잠재프로파일을 도출한 결과, 통계적 측면과 해석적 측면에서 다섯 개의 잠재프로파일이 가장 적합하였다. 공격성 과 사회적 위축에 따른 각각의 잠재프로파일은 중간 공격성/ 낮은 사회적 위축(25.1\%), 낮은 공격성/사회적 무관심 우세형 (5.7\%), 중간 공격성/중간 사회적 위축(44.7\%), 낮은 공격성/ 높은 갈등적 수줍음·사회적 무관심(11.4\%), 높은 공격성/높은 사회적 위축(13.1\%)으로 구분되었다.

이러한 결과는 공격성과 사회적 위축의 수준에 따라 네 개 의 잠재집단을 나누었던 기존 연구결과(Farmer, 2000; Ladd \& Burgess, 1999; Ledingham \& Schwartzman, 1984)와 다소 상이 한 양상으로 보인다. 이는 본 연구에서 공격성과 사회적 위축 의 하위유형을 고려하여 유아 개개인이 나타낼 수 있는 이질 성을 밝히고자 하였기 때문으로 볼 수 있다. 이러한 결과는 유 아의 공격성과 사회적 위축은 개개인마다 다소 상이한 양상을 보이며, 유아 개개인의 공격성과 사회적 위축 수준에 따라 개 입이 달라져야 함을 시사한다. 
가장 많은 유아가 속해있는 중간 공격성/중간 사회적 위축 집단은 공격성과 사회적 위축이 평균 수준으로 나타났으며, 그 다음으로 많은 중간 공격성/낮은 사회적 위축 집단은 공격 성이 중간 수준으로 나타났다. 유아기는 낮선 환경에 적응하 며 또래와의 관계 속에서 끊임없는 갈등을 경험하게 되고 이 러한 상황에서 유아에게 문제행동이 나타나기도 한다. 이와 관련하여 유아교육기관의 한 학급 내 약 $40 \%$ 의 유아가 높은 수준은 아니지만 하루에 1 회 이상 문제행동을 보이며, 약 $10 \%$ 정도의 유아는 하루 6회 이상 문제행동을 보인다는 보고가 있 다(Willoughby, Kupersmidt, \& Bryant, 2001). 일반적으로 유아 기 동안 나타나는 문제행동은 시간의 흐름에 따라 지속적으로 감소한다(S. Kim, 2018; K. S. Lee et al., 2004). 이는 유아의 사 회인지능력, 언어능력, 의사소통능력 및 자기조절능력이 발 달함에 따라 문제행동이 점차 감소하는 것으로(Hill, Degnan, Calkins, \& Keane, 2006; Olson, Choe, \& Sameroff, 2017), 본 연 구에서 확인된 중간 공격성/중간 사회적 위축 집단과 중간 공 격성/낮은 사회적 위축 집단은 유아기 일반적인 특성을 나타 내는 것으로 해석할 수 있다.

높은 공격성/높은 사회적 위축 집단은 신체적 공격성, 관계 적 공격성, 갈등적 수줍음, 사회적 무관심, 사회적 회피가 모 두 높게 나타났다. 이는 유아의 외현화 문제와 내재화 문제가 같이 나타날 수 있다는 선행연구(Keiley et al., 2003; J. R. Lee et al., 2017; Lilienfeld, 2003)를 지지하며 공격성과 사회적 위축 이 함께 나타난 선행연구(Farmer, 2000; Ladd \& Burgurse, 1990; Ledingham \& Schwartzman, 1984)와 일치하는 연구결과이다. 선행연구에서 외현화 문제와 내재화 문제를 함께 보이는 유 아, 그리고 공격성과 사회적 위축을 함께 보이는 유아는 다른 유아들과 비교하여 또래관계와 기관적응에 있어 부적응적인 특징을 보인다고 하였다(Ladd \& Burgess, 1999; J. R. Lee et al., 2017). 이를 바탕으로 높은 공격성/높은 사회적 위축 집단이 다른 집단과 비교하여 가장 부적응을 경험할 가능성이 높다 고 해석할 수 있다. 또한 높은 공격성/높은 사회적 위축 집단 은 다섯 개의 잠재집단 중 신체적 공격성, 관계적 공격성과 사 회적 회피 수준이 가장 높게 나타났는데 이는 사회적 회피가 공격성과 관련성이 있다는 선행연구(Asendorpf, 1990; Coplan et al., 2018)를 지지하는 결과이다. 이러한 특징을 가진 높은 공격성/높은 사회적 위축 집단은 사회적 회피로 설명할 수 있 다. 사회적 회피는 수줍은 아동이 타인과의 상호작용 동안 느 껴지는 두려움과 사회적 평가에 대한 걱정이 너무 강해져 사 회적 접근 동기가 점차 사라지고(Schmidt \& Fox, 1999), 부정 적인 또래 경험으로 인해 사회적 회피 동기가 강해진 것으로
(Coplan et al., 2014) 극단적인 수줍음의 형태로 보기도 한다. 이처럼 사회적 회피 유아는 갈등적 수줍음 유아나 사회적 무 관심 유아보다 복잡한 내면의 어려움을 가지고 있으므로 기 관에서 부적응을 경험할 가능성이 가장 크다. 실제로 사회적 회피 유아가 여러 내재화 문제를 가지고 있으며, 높은 사회적 불안과 우울을 경험하고 있음이 보고되고 있다(Coplan et al., 2018). 따라서 높은 공격성/높은 사회적 위축 집단에 속하는 유아의 교육기관 적응을 효과적으로 돕기 위해서 이 집단유형 에 대한 이해를 바탕으로 개별적 접근이 필요하다. 하지만 높 은 공격성/높은 사회적 위축 집단을 설명할 수 있는 사회적 회 피 유아 및 공격성과 사회적 위축을 함께 보이는 유아에 대한 연구는 부족한 실정이다. 그러므로 추후 연구에서 사회적 회 피 및 공격성과 사회적 위축이 함께 나타나는 유아를 고유한 특성을 가진 유형으로 구분하여 다뤄져야 하며, 이를 바탕으 로 높은 공격성/높은 사회적 위축 집단 유아의 적응을 도모함 이 필요하다.

또한 각 잠재프로파일은 신체적 공격성과 관계적 공격성에 서 차이가 나타나지 않고 사회적 위축 유형(갈등적 수줍음, 사 회적 무관심, 사회적 위축)에 따라 그 프로파일 특징이 다르게 나타났다. 사회적 위축 특징을 가진 잠재집단으로 낮은 공격 성/사회적 무관심 우세형 집단과 낮은 공격성/높은 갈등적 수 줍음.사회적 무관심 집단을 확인하였다. 이를 통해 유아들이 사회적 위축에서 다양한 프로파일을 가지고 있음을 경험적으 로 확인할 수 있다. 사회적 위축을 보이는 유아는 표면적으로 타인과 의사소통이 적은 것으로 보이지만 본 연구 결과처럼 서로 다른 특징을 가진 유형들로 분류가 가능하며, 이는 사회 적 위축 유아의 개별적 접근이 필요함을 시사한다.

한편, 유아의 공격성과 사회적 위축 잠재프로파일에서 공 격성 수준의 차이는 나타났지만 신체적 공격성과 관계적 공격 성 간의 차이가 나타나지 않았다. 이는 신체적 공격성과 관계 적 공격성 수준에 따라 신체적 공격성 집단, 관계적 공격성 집 단, 신체적.관계적 공격성 집단으로 구분한 선행연구와 상이 한 결과이다(Shin, 2008). 선행연구에 의하면 관계적 공격성은 3세경에 나타나기 시작하며(Crick, 1997), 여아에게서 많이 발 생하는 것으로 보고된다(Crick \& Grotpeter, 1995). 그러나 남 아, 여아 모두 관계적 공격성을 신체적 공격성과 마찬가지로 또래가 화나게 하는 상황에 대한 반응으로 받아들이고 있다 는 보고가 있다(Goldstein, Tisak, \& Boxer, 2002). 즉 화가 나는 상황에서 표현이 미숙한 유아들은 신체적 공격성 만큼 관계적 공격성을 나타낼 수 있다고 볼 수 있다. 또한 관계적 공격성은 또래와 상호작용과정에서 친구에게 소외감을 느끼도록 관계 
를 조절하고 자신의 공격행동을 정당화하여 주변 사람들이 수 용할 수 있게 하는 행동으로 언어능력, 사회적 이해 및 기술과 같은 사회적 능력 그리고 마음이론과 관련 있다고 보고된다 (Crick, 1997; Shin, 2008; Sutton, Smith, \& Swettenham, 1999). 본 연구는 4 세와 5 세를 대상으로 한 선행연구와 달리 언어능 력, 사회적 능력과 마음이론 발달이 초기단계인 3세가 포함되 어 신체적 공격성과 관계적 공격성의 뚜렷한 차이가 나타나지 않은 것으로 볼 수 있다.

둘째, 유아의 공격성과 사회적 위축 잠재프로파일 유형에 따른 또래유능성 차이를 분석하였다. 사교성은 중간 공격성/ 낮은 사회적 위축 집단이 가장 높고 그 다음으로 낮은 공격성/ 사회적 무관심 우세형 집단과 중간 공격성/중간 사회적 위축 집단이, 그 다음으로 높은 공격성/높은 사회적 위축 집단과 낮 은 공격성/높은 갈등적 수줍음.사회적 무관심 집단 순으로 나 타났다. 친사회성은 낮은 공격성/사회적 무관심 우세형 집단 이 가장 높고, 중간 공격성/낮은 사회적 위축 집단이 중간 공 격성/중간 사회적 위축 집단과 높은 공격성/높은 사회적 위축 집단보다 높은 것으로 나타났다. 마지막으로, 주도성은 중간 공격성/낮은 사회적 위축 집단이 가장 높고, 중간 공격성/중간 사회적 위축 집단이 높은 공격성/높은 사회적 위축 집단과 낮 은 공격성/높은 갈등적 수줍음.사회적 무관심 집단보다 높았 으며 낮은 공격성/높은 수줍음.무관심 집단이 가장 낮은 것으 로 나타났다.

우선 사교성은 낮은 공격성/높은 갈등적 수줍음- 사회적 무 관심 집단과 높은 공격성/높은 사회적 위축 집단이 가장 낮은 것으로 나타났다. 이는 갈등적 수줍음 유아와 사회적 회피 유 아가 또래문제를 보인다는 선행연구(Coplan et al., 2018)와 공 격성과 위축을 함께 보이는 유아가 또래관계에서 어려움을 겪 는다는 선행연구와 그 맥을 같이 한다(Ladd \& Burgess, 1999). 사교성은 또래집단에 잘 수용되며 여러 아이들과 어울릴 수 있는 능력으로 낮은 공격성/높은 갈등적 수줍음·사회적 무관 심 유아는 내면에서 접근 동기와 회피 동기가 갈등하여 또래 에게 먼저 다가가는 것이 어렵기 때문에 낮은 사교성을 보이 는 것으로 해석된다. 이러한 수줍은 아동을 돕기 위해 Brophy (1996)는 또래 개입과 교사 개입을 제안하였다. 또래 개입의 경우 수줍은 아동을 위해 연령을 교차한 튜터링 프로그램을 통해 또래와 상호작용할 수 있는 기회를 만들어 주는 것이 중 요함을 제안하였다. 이처럼 내면적 갈등으로 또래에게 다가가 기가 어려운 갈등적 수줍음 유아에 또래와 상호작용의 기회를 만들어 주는 프로그램이 수줍은 유아의 또래관계 형성과 기관 적응에 도움이 될 것이다. 또한 교사가 사회적 환경을 바꾸어
줌으로써 개입할 수 있다. 예를 들어 수줍음 유아를 친근한 친 구들 사이에 앉히거나, 수줍은 유아의 작은 스트레스나 난처 한 상황에 민감하게 반응함으로써 수줍은 유아의 적응을 도울 수 있다. 높은 공격성/높은 사회적 위축 집단은 사회적 회피의 특징을 가진 집단으로 낮은 접근 동기와 높은 회피 동기로 또 래와 상호작용을 적극적으로 피하는 특징 때문에 사교성이 낮 은 것으로 해석된다. 높은 공격성/높은 사회적 위축 집단은 또 래와 어울리지 못하는 그 내면적 어려움을 이해하는 것이 중 요하다. 하지만 이 집단에 대한 연구가 부족한 실정이므로 사 회적 회피의 특징을 가진 높은 공격성/높은 사회적 위축 집단 을 이해하기 위한 후속 연구가 이루어질 필요가 있다.

친사회성은 낮은 공격성/사회적 무관심 우세형 집단이 가 장 높은 것으로 나타났다. 이는 사회적 무관심 유아가 또래 문 제를 보이지 않고, 다른 사회적 위축 유형보다 사회적으로 유 능하고 사회적 상호작용에 두려움이 없다는 선행연구와 맥 을 같이 한다(Asendorpf, 1990; Coplan et al., 2004; Coplan et al., 2018; Harrist et al., 1997). 사회적 무관심 유아는 낮은 접근 동 기로 다른 유아와 상호작용이 적고 또래보다는 장난감과 같은 사물에 더 흥미를 보이지만, 낮은 회피 동기로 다른 유아와 상 호작용할 때 불편해하지 않는다(Asendorpf, 1990). 사회적 무관 심 유아는 갈등적 수줍음 유아와 사회적 회피 유아 보다 부적 응에 있어 비교적 경미한 것으로 나타나지만, 비교적 낮은 사 회적 접근 동기로 인해 나타나는 유아의 행동들이 시간이 지 나 또래 사이에서 덜 호감 가는 특징이 될 때 또래 거절로 이어 질 수 있기 때문에(Coplan, Rose-Krasnor, Weeks, Kingsbury, \& Bullock, 2013; Harrist et al., 1997) 주의를 기울일 필요가 있다.

또한, 주도성의 경우 낮은 공격성/높은 갈등적 수줍음.사 회적 무관심 집단이 가장 낮은 것으로 나타났다. 이러한 연 구결과는 갈등적 수줍음 유아가 불안과 또래 사이에서 고립 이 높고 사회적 기술이 낮다는 선행연구와 그 맥을 같이 한다 (Harrist et al., 1997). 주목할 점은 본 연구에서 확인한 다섯 개 의 잠재집단유형이 공격성 수준에 따라 주도성에서 차이가 나 타난 것이다. 낮은 수준의 공격성을 보이는 낮은 공격성/높은 갈등적 수줍음·사회적 무관심 집단은 중간 수준의 공격성을 보이는 중간 공격성/중간 사회적 위축 집단과 중간 공격성/낮 은 사회적 위축 집단보다 주도성이 유의미하게 낮았다. 또한 가장 낮은 수준의 공격성을 보인 낮은 공격성/사회적 무관심 우세형 집단은 사교성이 중간 공격성/중간 사회적 위축 집단 과 차이가 없었으며 친사회성은 다섯 집단 중 가장 높은 점수 를 보였지만, 주도성에선 중간 공격성/낮은 사회적 위축 집단 보다 낮고 높은 공격성/높은 사회적 위축 집단과 유의미한 차 
이를 보이지 않았다. 이는 갈등적 수줍음과 사회적 무관심이 낮은 공격성 수준을 보인다는 선행연구(Asendorpf, 1990)와 일 치하는 결과이다. 공격성이 낮은 낮은 공격성/높은 갈등적 수 줍음.사회적 무관심 집단과 낮은 공격성/사회적 무관심 우세 형 집단이 낮은 주도성 수준을 보인 결과는 사회적으로 위축 된 유아들이 또래와 어울려 지내는 것과 사이좋게 지내는 것 보다 또래집단에서 활동이나 놀이를 능동적으로 제안하고 자 신의 의견을 효과적으로 주장하는 데 어려움이 있음을 알 수 있다. 이러한 결과는 두 집단에 속하는 유아의 교육기관 적응 을 돕기 위해서 주도성을 증진시킬 수 있는 프로그램을 계획 하는 것이 필요함을 시사한다.

본 연구는 잠재프로파일 분석을 활용하여 유아의 공격성과 사회적 위축에 따른 다양한 양상을 경험적으로 확인하였으며, 이를 통해 유아의 공격성과 사회적 위축에 대한 이해를 확장 한 것에 의의가 있다. 이를 바탕으로 각 잠재집단유형별 교육 기관 적응을 위한 구체적인 제안점은 다음과 같다.

먼저, 유아의 공격성과 사회적 위축의 다양한 잠재집단유 형을 확인한 결과는 유아교육기관에서 유아에게 다양한 문제 행동 유형이 나타날 수 있음을 이해하는 것이 중요함을 시사 한다. 유아의 문제행동이 여러 양상으로 나타남을 이해하는 것은 문제행동 유형에 따라 유아의 기관 적응을 위한 개입과 중재의 방법이 달라져야 하는 기본 전제조건이 되기 때문에 중요하다. 따라서 교사나 부모가 유아의 문제행동의 다양성을 이해하고 인지할 수 있도록 교육하는 것이 필요하다.

중간 공격성/중간 사회적 위축 집단과 중간 공격성/낮은 사 회적 위축 집단은 대부분의 유아가 속한 집단으로 유아들이 일반적으로 공격적인 행동을 보일 수 있음을 이해하는 것이 필요하다. 이는 유아기에 사회적 기술, 의사소통 능력 등의 발 달이 미숙한 결과(Hill et al., 2006; Olson et al., 2017)로 유아가 사회적 상황에 맞게 적절히 자신의 감정이나 생각을 표현할 수 있도록 도와주는 것이 필요하다.

낮은 공격성/사회적 무관심 우세형 집단은 낮은 공격성/높 은 갈등적 수줍음 - 사회적 무관심 집단과 높은 공격성/높은 사회적 위축 집단보다 사교성이 높고 다섯 집단 중 친사회성 이 가장 높아 공격성과 사회적 회적 위축이 높은 높은 공격성/ 높은 사회적 위축 집단과 낮은 공격성/높은 갈등적 수줍음 · 사회적 무관심 집단과 비교하여 비교적 완만하게 또래관계를 형성하는 것으로 보인다. 하지만 낮은 공격성/사회적 무관심 우세형 집단 유아는 또래보다 장난감과 같은 사물에 더 흥미 를 보일 수 있어 비교적 적은 양의 상호작용을 경험할 수 있다 (Asendorpf, 1990). 유아기는 타인과 관계를 통해 사회적 기술
을 습득하는 시기로, 이 시기 타인과 상호작용의 양과 질은 이 후 건강한 관계 발달에 필수적이다(Asher \& Coie, 1990). 따라 서 낮은 공격성/사회적 무관심 우세형 집단 유아들에게 또래 및 다양한 관계를 경험할 수 있도록 격려하는 것이 필요하다.

또한 낮은 주도성을 보인 낮은 공격성/사회적 무관심 우세 형 집단과 낮은 공격성/높은 갈등적 수줍음 - 사회적 무관심 집 단 유아들이 자신의 의견 또는 생각을 타인에게 표현할 수 있 도록 격려할 필요가 있다. 더불어 낮은 공격성/높은 갈등적 수 줍음-사회적 무관심 집단 유아는 사회적 참여에 대한 내면적 갈등으로 사회적 상호작용에 참여하는 것을 어려워하므로 교 사가 또래와 상호작용할 수 있는 기회를 만들어 주는 중재자 역할이 필요하다.

마지막으로, 높은 공격성/높은 사회적 위축 집단의 적응을 돕기 위해 우선 그들의 내면적 동기를 이해하는 것이 필요하 다. 또한 높은 공격성/높은 사회적 위축 집단 유아는 부정적인 관계의 경험으로 인해 회피 동기가 높아진 것이므로, 주 양육 자나 교사와 같은 안정된 관계 속에서 긍정적인 관계의 경험 을 할 수 있도록 도와주는 것이 필요하다.

마지막으로 본 연구의 제한점과 함께 이를 토대로 후속 연 구를 위한 제언은 다음과 같다.

첫째, 본 연구는 유아기 공격성과 사회적 위축 잠재집단유 형을 단일 시점에서 살펴보았기 때문에 시간이 지남에 따라 잠재집단유형이 어떻게 발달하는지에 대해 고려하지 못하였 다. 따라서 후속 연구에서는 여러 시점에 걸쳐 측정된 종단자 료로 아동의 공격성과 사회적 위축이 연령이 증가함에 따라 어떻게 달라지는지 발달과정을 규명하고 이후 교육기관 적응 과 어떤 관련성이 있는지 밝힐 필요가 있다.

둘째, 본 연구에서 사용한 사회적 위축 척도는 국외에서 개 발되어 타당화가 이루어진 척도로 국내 초기 적용단계이다. 향후에는 우리나라에서 적용 가능한지 타당화를 거쳐 척도를 사용할 필요가 있다.

셋째, 공격성, 사회적 위축, 또래유능성의 각 하위요인간 상 관이 높게 나타났다. 이는 교사의 보고에 의해서만 측정되어 유아의 행동들간의 상관이 높게 나타난 것으로 보인다. 후속 연구에서 교사뿐만 아니라 부모의 보고를 함께 고려할 필요가 있다.

넷째, 본 연구는 유아의 공격성과 사회적 위축 잠재집단유 형 따른 또래유능성 차이를 살펴보았는데 향후 연구에서 공격 성과 사회적 위축에 영향을 미치는 개인·환경 요인을 파악하 여 유아의 공격성과 사회적 위축의 이해를 확장시키고 예방을 위한 기초자료를 마련할 필요가 있다. 
이러한 제한점에도 불구하고, 본 연구는 잠재프로파일 분 석을 활용하여 유아의 공격성과 사회적 위축에 따라 분류된 각각의 집단의 특성과 또래유능성의 차이를 살펴보았기 때문 에 유아 개개인이 나타낼 수 있는 공격성과 사회적 위축을 고 려하여 차별화된 프로그램과 적절한 개입과 방안을 제안한 것 에 의의가 있다.

\section{Notes}

This article is a part of the first author's master's thesis submitted in 2019, and was presented as a poster at the 2019 Annual Spring Conference of the Korean Association of Child Studies.

\section{Conflict of Interest}

No potential conflict of interest relevant to this article was reported.

\section{References}

\section{In English}

Achenbach, T. M., \& Edelbrock, C. S. (1983). Manual for the child behavior checklist and revised child behavior profile. Burlington, VT: University of Vermont.

Asendorpf, J. B. (1990). Beyond social withdrawal: Shyness, unsociability, and peer avoidance. Human Development, 33, 250-259. doi:10.1159/000276522

Asher, S. R., \& Coie, J. D. (1990). Peer rejection in childhood. New York: Cambridge University Press.

Bergman, L. R., \& Magnusson, D. (1997). A person-oriented approach in research on developmental psychopathology. Development and Psychopathology, 9(2), 291-319. doi:10.1017/S095457949700206X

Björkqvist, K., Österman, K., \& Kaukiainen, A. (1992). The development of direct and indirect aggressive strategies in males and females. In K. Björkqvist \& P. Niemelä (Eds.), Of mice and women: Aspects of female aggression (pp. 51-64). San Diego, CA: Academic Press.

Brophy, J. (1996). Working with shy or withdrawn students. Retrieved from https://eric.ed.gov

Coplan, R. J., Ooi, L. L., Rose-Krasnor, L., \& Nocita, G. (2014). 'I want to play alone': Assessment and correlates of self-reported preference for solitary play in young children. Infant and Child Development, 23(3), 229-238. doi:10.1002/icd.1854

Coplan, R. J., Ooi, L. L., Xiao, B., \& Rose-Krasnor, L. (2018). Assessment and implications of social withdrawal in early childhood: A first look at social avoidance. Social Development, 27(1), 125-139. doi:10.1111/sode.12258

Coplan, R. J., Prakash, K., O’Neil, K., \& Armer, M. (2004). Do you "want" to play? Distinguishing between conflicted shyness and social disinterest in early childhood. Developmental Psychology, 40(2), 244-258. doi:10.1037/0012-1649.40.2.244

Coplan, R. J., Rose-Krasnor, L., Weeks, M., Kingsbury, A., Kingsbury, M., \& Bullock, A. (2013). Alone is a crowd: Social motivations, social withdrawal, and socioemotional functioning in later childhood. Developmental Psychology, 49(5), 861-875. doi:10.1037/a0028861

Coplan, R. J., \& Weeks, M. (2009). Shy and soft-spoken: Shyness, pragmatic language, and socio-emotional adjustment in early childhood. Infant and Child Development, 18(3), 238254. doi: $10.1002 /$ icd.622

Crick, N. R. (1997). Engagement in gender normative versus nonnormative forms of aggression: Links to socialpsychological adjustment. Developmental Psychology, 33(4), 610-617. doi:10.1037/0012-1649.33.4.610

Crick, N. R., \& Grotpeter, J. K. (1995). Relational aggression, gender, and social-psychological adjustment. Child Development, 66(3), 710-722. doi:10.2307/1131945

Farmer, Jr., A. D. (2000). Children at risk: Predictors and consequences of comorbid aggressive-withdrawn problem profiles in early grade school (Doctoral dissertation). Retrieved from http://www.riss. $\mathrm{kr} /$ link?id=T10564059

Goldstein, S. E., Tisak, M. S., \& Boxer, P. (2002). Preschoolers' normative and prescriptive judgments about relational and overt aggression. Early Education and Development, 13(1), 23-40. doi:10.1207/s15566935eed1301_2

Harrist, A. W., Zaia, A. F., Bates, J. E., Dodge, K. A., \& Pettit, G. S. (1997). Subtypes of social withdrawal in early childhood: Sociometric status and social-cognitive differences across four years. Child Development, 68(2), 278-294. doi: $10.2307 / 1131850$

Hill, A. L., Degnan, K. A., Calkins, S. D., \& Keane, S. P. (2006). Profiles of externalizing behavior problems for boys and girls across preschool: The roles of emotion regulation and inattention. Developmental Psychology, 42(5), 913-928. doi:10.1037/0012-1649.42.5.913

Johnson, C., Ironsmith, M., Snow, C. W., \& Poteat, G. M. (2000). Peer acceptance and social adjustment in preschool and kindergarten. Early Childhood Education Journal, 27(4), 207-212. doi:10.1023/B:ECEJ.0000003356.30481.7a

Keiley, M. K., Lofthouse, N., Bates, J. E., Dodge, K. A., \& Pettit, 
G. S. (2003). Differential risks of covarying and pure components in mother and teacher reports of externalizing and internalizing behavior across ages 5 to 14. Journal of Abnormal Child Psychology, 31(3), 267-283. doi:10.1023/ A: 1023277413027

Ladd, G. W., \& Burgess, K. B. (1999). Charting the relationship trajectories of aggressive, withdrawn, and aggressive/ withdrawn children during early grade school. Child Development, 70(4), 910-929. doi:10.1111/1467-8624.00066

Ladd, G. W., Price, J. M., \& Hart, C. H. (1990). Preschoolers' behavioral orientations and patterns of peer contact: Predictive of peer status? In S. R. Asher \& J. D. Coie (Eds.), Peer rejection in childhood (pp. 90-115). New York: Cambridge University Press.

Ledingham, J. E., \& Schwartzman, A. E. (1984). A 3-year followup of aggressive and withdrawn behavior in childhood: Preliminary findings. Journal of Abnormal Child Psychology, 12(1), 157-168. doi:10.1007/BF00913467

Lee, J. R., Kim, G., Yi, Y., Song, S., \& Kim, J. (2017). Classifying Korean children's behavioral problems and their influencing factors: A latent profile analysis. International Journal of Child Care and Education Policy, 11(6), 1-17. doi:10.1186/ s40723-016-0026-2

Lilienfeld, S. O. (2003). Comorbidity between and within childhood externalizing and internalizing disorders: Reflections and directions. Journal of Abnormal Child Psychology, 31(3), 285291. doi:10.1023/A:1023229529866

Mplus (Version 8.1). [Computer software]. Los Angeles, CA: Muthén \& Muthén.

Olson, S. L., Choe, D. E., \& Sameroff, A. J. (2017). Trajectories of child externalizing problems between ages 3 and 10 years: Contributions of children's early effortful control, theory of mind, and parenting experiences. Development and Psychopathology, 29(4), 1333-1351. doi:10.1017/ S095457941700030X

Rubin, K. H., Coplan, R. J., \& Bowker, J. C. (2009). Social withdrawal in childhood. Annual Review of Psychology, 60, 141-171. doi:10.1146/annurev.psych.60.110707.163642

Rubin, K. H., Daniels-Beirness, T., \& Bream, L. (1984). Social isolation and social problem solving: A longitudinal study. Journal of Consulting and Clinical Psychology, 52(1), 17-25. doi:10.1037/0022-006X.52.1.17

Schmidt, L. A., \& Fox, N. A. (1999). Conceptual, biological, and behavioral distinctions among different categories of shy children. In L. A. Schmidt \& J. Schulkin (Eds.), Series in affective science: Extreme fear, shyness, and social phobia: Origins, biological mechanisms, and clinical outcomes (pp. 47-66). New York: Oxford University Press.

Sutton, J., Smith, P. K., \& Swettenham, J. (1999). Socially undesirable need not be incompetent: A response to
Crick and Dodge. Social Development, 8(1), 132-134. doi:10.1111/1467-9507.00085

Willoughby, M., Kupersmidt, J., \& Bryant, D. (2001). Overt and covert dimensions of antisocial behavior in early childhood. Journal of Abnormal Child Psychology, 29(3), 177-187. doi:10.1023/A:1010377329840

Younger, A. J., \& Daniels, T. M. (1992). Children's reasons for nominating their peers as withdrawn: Passive withdrawal versus active isolation. Developmental Psychology, 28(5), 955-960. doi:10.1037/0012-1649.28.5.955

\section{In Korean}

Kim, J. H. (2010). Aggression, atrophic, and relation to peer group by children's gender: Focus on familiarity and arbitration influence of mother and teacher (Master's thesis). Retrieved from http://www.riss.kr/link?id=T12130220

Kim, M. S., Ha, E. H., \& Oh, K. J. (2014). A cluster analysis of K-CBCL for outpatient children. The Korean Journal of Clinical Psychology, 33(4), 675-693.

Kim, S. (2018). Trajectories of externalizing behavior problems in young children and its associations with elementary school adjustment and executive function difficulties: Using growth mixture modeling. Korean Journal of Child Studies, 39(6), 41-56. doi:10.5723/kjcs.2018.39.6.41

Kim, S. Y., \& Jung, J. (2001). Yuaui ttoraesuyongdo, jeongseojineung, jeogeunghaengdonggwaui gwangye [유 아의 또래수용도, 정서지능, 적응행동과의 관계]. Korea Journal of Child Care and Education 26, 239-257.

Ko, B., \& Sung, J. (2019). Relationship between young children's social withdrawal and preschool adjustment: The moderating effects of teacher-child relationships and maternal management strategies for children's peer relationships. The Korean Journal of Developmental Psychology, 32(1), 45-67. doi:10.35574/KJDP.2019.03.32.1.45

Lee, K. S., Shin, Y. J., Chun, Y. J., \& Park, J. A. (2004). The characteristics of behavior problem among young children in Korea. The Korean Journal of Developmental Psychology, 17(4), 53-74.

Park, J., \& Rhee, U. (2001). Development of a peer competence scale for preschool children. Journal of the Korean Home Economics Association, 39(1), 221-232.

Park, J. Y., Kang, S. D., \& Kwon, K. S. (2010). The relations among children's temperament and peer competence, maternal child-rearing attitudes, and the children's behavioral problems. Journal of Future Early Childhood Education, 17(4), 139-162.

Shin, Y. (2008). Physical and relational aggression in preschoolers: Gender differences and links to language ability and social competence. Korean Journal of Early Childhood Education, 
28(2), 95-111.

Shin, Y. (2009). The role of gender in moderating effects of language ability, prosocial behavior, and friendship on the links between social withdrawal and peer rejection. Korean Journal of Early Childhood Education, 29(3), 149-163.

Yoon, S. J., \& Kim, M. K. (2011). Teacher-child relationships and peer relationships by young children's aggression. Journal of Korean Child Care and Education, 7(4), 49-68.

\section{ORCID}

Yie Lae Kim http://orcid.org/0000-0002-0436-4640

Sunhee Kim http://orcid.org/0000-0002-0801-6918

Received June 30, 2019

Revision received July 23, 2019

Accepted July 31, 2019 